\title{
The Design of humanoid Robot Arm based on Morphological and Neurological Analysis of Human Arm
}

\author{
Yongseon Moon ${ }^{1}$, Nak Yong $\mathrm{Ko}^{2}$ and Youngchul Bae ${ }^{3}$ \\ ${ }^{1}$ School of Information Communication Sunchon National Universit, \\ Suncheon,5407-42.Korea, moon@sunchon.ac.kr \\ 2 Department of Control and Instrumentation Engineering, Chosun University, \\ Gwangju,550-759,Korea, nyko@chosun.ac.kr \\ ${ }^{3}$ Division of Electrical-Electronic Communication.Computer Engineering, Chonnam \\ National University, \\ Yeosu,550-745, Korea, ycbae@chonnam.ac.kr
}

\begin{abstract}
In this paper, we analyzed and verified possibility and validity of overcoming present limitations of humanoid robot by using morphological and neurological analysis of human arm. Through design, implementation and performance evaluation of humanoid robot arm, we will be verifying applicability and effectiveness of humanoid robot arm system based on SERCOS network that fulfills the concept of opening, networking and modularizations that are progressive direction of future robot.

Index Terms - humanoid robot, UML, ISO 15745, SERCOS Communication
\end{abstract}

\section{Introduction}

At first appearance of the industrial robots during the 1960s, the concepts for the usage of the robots were only as manipulator in which to perform pre-ordered commands. After 20 years later during the 1980s, together with the appearance of microprocessor, it marked the beginning of the intense research of the field of robot. As the research progressed, robots were recognized not only as simple action performer but as a machine that have diverse and variety of purposes and usages.

As the technology and recognition of robots improved in a variety of ways, humans began to relate themselves with robots; hence, these robots are called humanoid robot in which they resemble appearance of human and imitate their behaviour. There are two representative humanoid robots that have currently developed. They are Japanese Honda's ASIMO which is well known as superior to any other humanoid robots and KAIST's HUBO.

However, these robots have some limiting factors. First, they have limited control performance due to DC motor usage for joint actuator and difficulty in constant repairing and replacement of joint that are caused by wearing down of brush and commutator. These factors cause limited life time of robots, which in turn brings economic burden. Second, 
current robot control networks are RS-232[2], USB(Universal serial bus)[3], CAN(Control area network)[4], Ethernet[5] which cannot sufficiently implemented the performance of humanoid robots. Third, current humanoid robot technology is focused on production and implementation of skills without proper mechanism for opening methodology of development for analysis, design, implementation, and integration for robot development.

In this paper, we analyzed and verified possibility and validity of overcoming present limitations of humanoid robot by using morphological and neurological analysis of human arm. Through design, implementation and performance evaluation of human robot arm, we will be verifying applicability and effectiveness of humanoid robot arm system based on SERCOS network that fulfills the concept of opening, networking and modularization that are progressive direction of future robot.

\section{The Development Methodology of Humanoid Robot Arm}

\section{A. Open human robot development methodology}

In order to establish a generalized opening technology system for the analysis, design, integration, and implementation of the humanoid robot, we proposed a new mechanism of development using generalized method of robot arm that is core make up component of the arm. Fig. 1 show open development methodology for humanoid robot arm based on ISO15745.

Opened humanoid robot development methodology begins from analysing morphological and neurological structure of human arm and through yielding of current developed humanoid robot arm model. Then, we develop a design integration model of humanoid robot arm using opening ISO15745 standardization criterion and definition. In ISO15745 standard, regulation is made by using UML (Unified modelling language) which is standard model of orientation in designing the humanoid robot arm. Humanoid robot arm designing integration class that has been finally deducted by using UML through another standardized transformation process for profile description is described as a XML(Extensible Markup Language) schema. Final design profile is prepared through instance of document of schema and process. These humanoid robot arm design profile that has been going through these processes is used as standard manual for robot arm development [6].

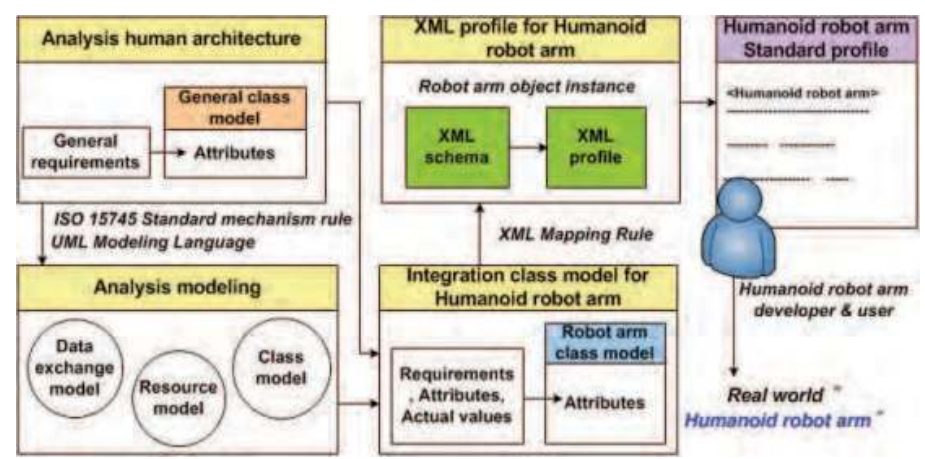

Fig. 1. ISO 15745 based open development methodology for humanoid robot arm development 


\section{B. Morphological analysis of human arm}

In this paper, we applied mapping concept of human morphological structure for implementation of robot arm that is similar to structure and movement to that of human arm. Fig. 2 show human -robot morphological mapping.

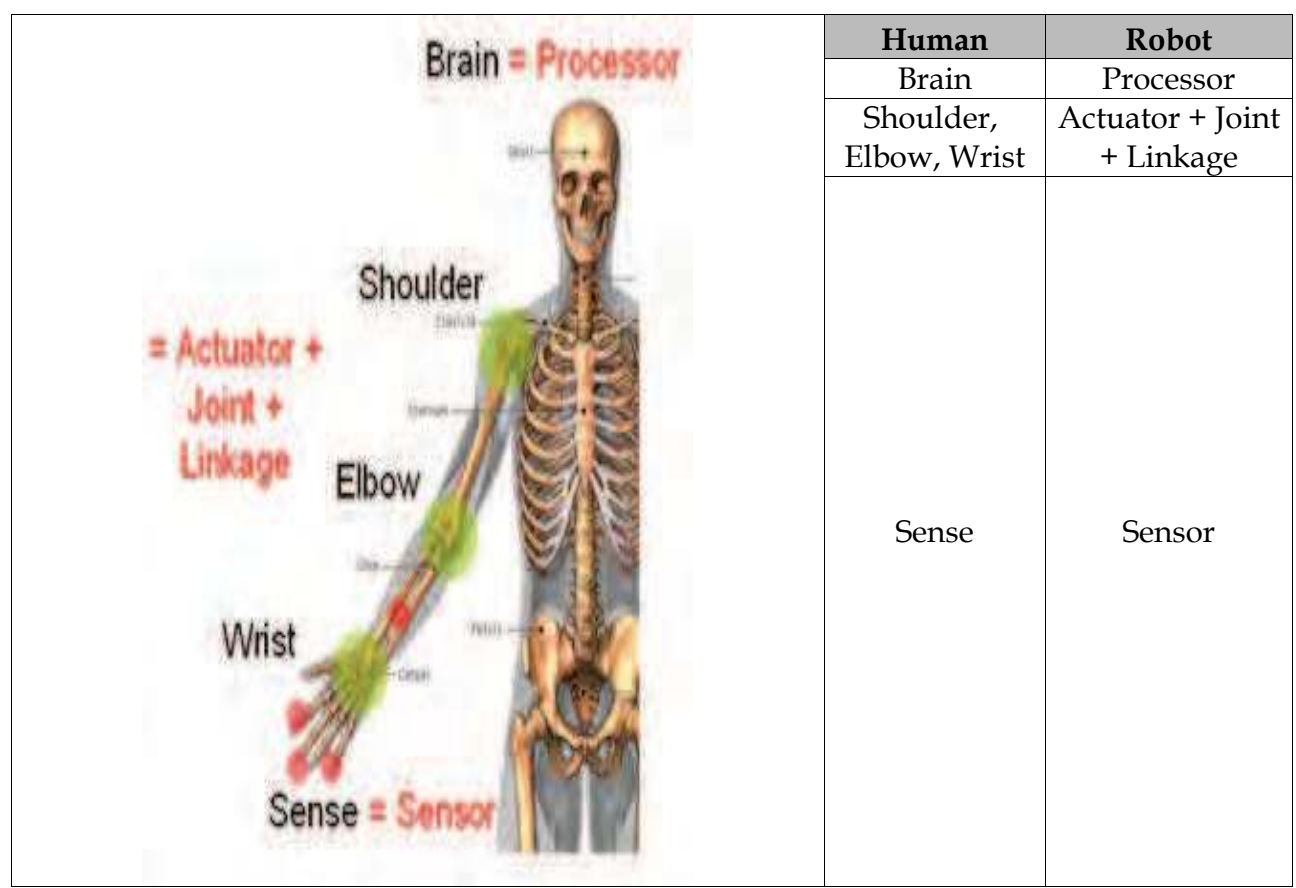

Fig. 2. Human-robot morphological mapping

\section{Neurological analysis of structure of human arm}

Through neurological analysis of structure of human [7], we define control network and processor structures for implementation of humanoid robot arm. Humans perform movement of muscles and acquire internal and external information through each organ based on nerve activity. These nerves can be viewed as robot's network in functional sense. Furthermore, according to human neurological classification, nervous system is classified in brain, spinal cord, sensorimotor. These can be matched with functional module of processor of robot control. Fig.3 shows a Human-robot neurological mapping.

\section{Modeling of Humanoid Robot Arm}

Based on requirement of robotic arm through neurological and morphological analysis, we can develop designing model for humanoid robot arm.

Table 1 present basic requirement for implementation of humanoid robot arms currently developed national and international wide through analysis of structure of humanoid robot arm and human morphology. 


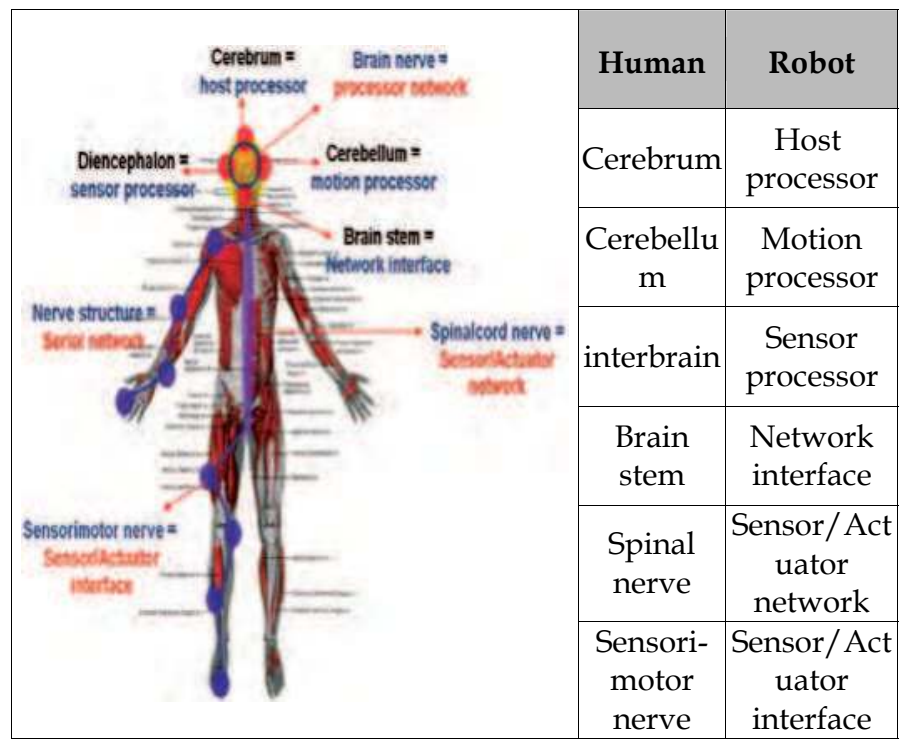

Fig. 3. Human-robot neurological mapping

\begin{tabular}{|c|c|c|}
\hline Item & Requirement & Reason \\
\hline Arm type & Module structure & $\begin{array}{l}\text { - Simplification of arm structure and wire problem } \\
\text { solving }\end{array}$ \\
\hline $\begin{array}{l}\text { Degree of } \\
\text { freedom }\end{array}$ & $5 \square 7$ & $\begin{array}{l}\text { - Optimal behavior implementation based on human } \\
\text { structure }\end{array}$ \\
\hline Actuator & AC servo motor & - High precision control and everlasting use of joint \\
\hline \multirow{3}{*}{$\begin{array}{l}\text { Control } \\
\text { network }\end{array}$} & $\begin{array}{l}\text { High speed } \\
\text { network }\end{array}$ & - High speed data processing \\
\hline & $\begin{array}{l}\text { Motion control } \\
\text { network }\end{array}$ & $\begin{array}{l}\text {-Advance performance of motion control and multi } \\
\text { axes synchronization }\end{array}$ \\
\hline & Serial network & $\begin{array}{c}\text { - Human nerve system, cable wire remove, and } \\
\text { modularization implementation }\end{array}$ \\
\hline
\end{tabular}

Table 1. The requirements for implementation of humanoid robot arms

\section{A. Humanoid robot arm resource integration model}

ISO15745 standard represents an integration model called AIF(Application Integration Model) which defines the opening development system. AIF integration model is subdivided into a process integration model, a data exchange model, and a resource integration model. Among these detailed models, we standardized them as resource integration mode to define external structure of system 1 .

Through this paper, we defined external structure and configuration of humanoid robot arm using resource integration model of ISO15745. (Fig. 4) 


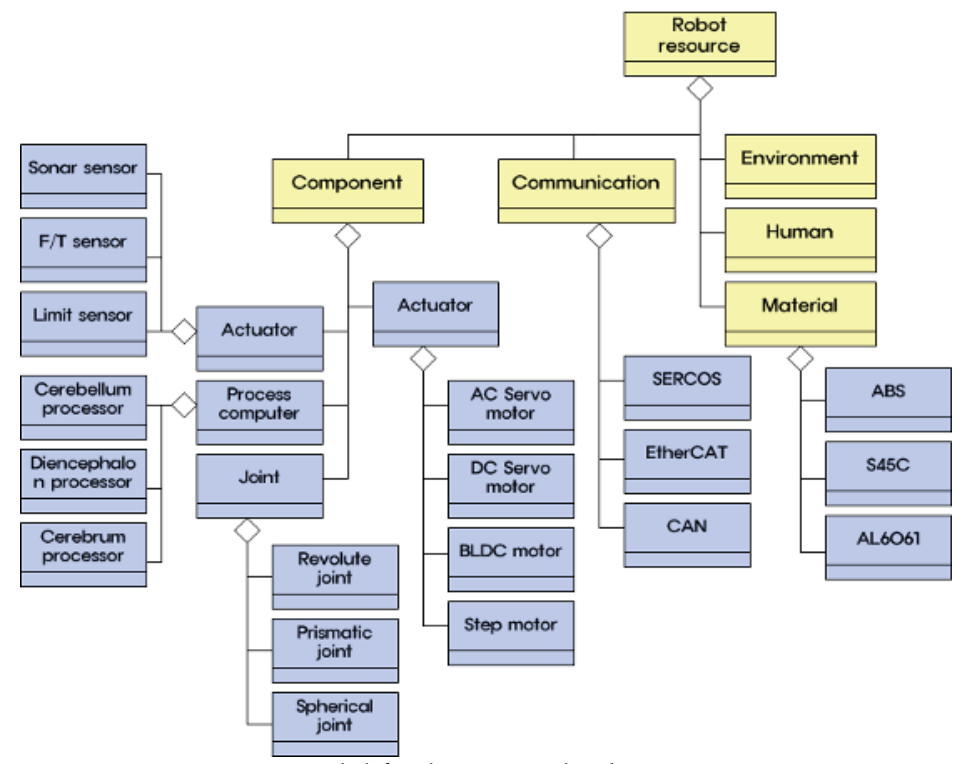

Fig. 4. The resource integration model for humanoid robot arm

\section{B. Humanoid robot arm data exchange model}

By using humanoid robot arm that behaves in ISO15745 standard that are based on human neurological and morphological transaction structure, we presented behaviour of internal system for movement of humanoid robot in the Fig. 5. [6]

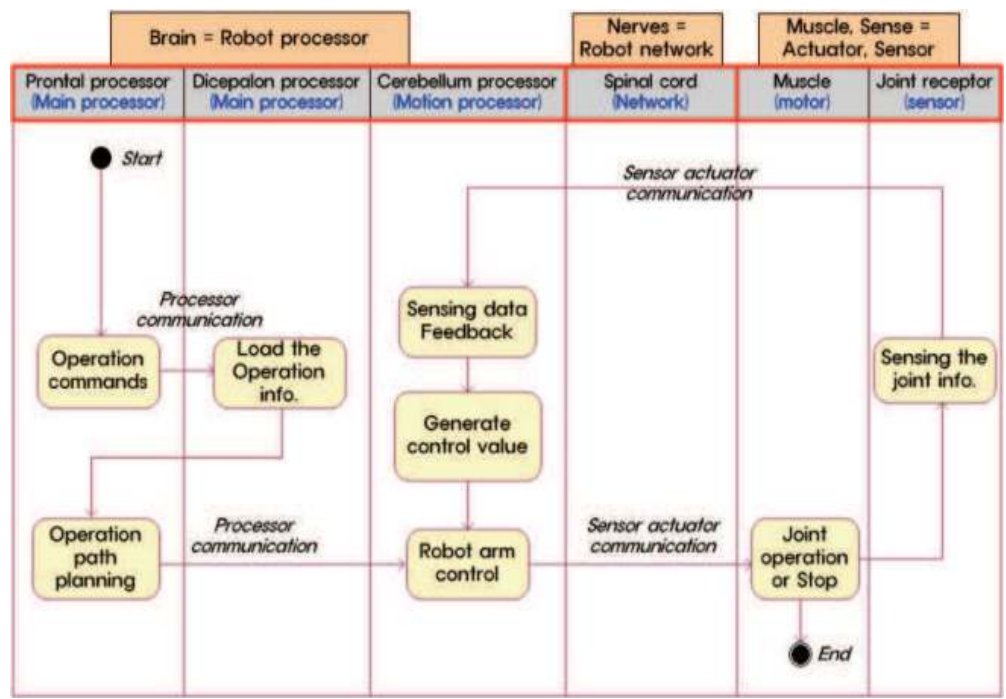

Fig. 5. The activity model for humanoid robot arms motion 


\section{Humanoid robot arm integration model}

Through analysis of human arm movement and control component, the final designed model of humanoid arm that are based on human structure like Fig. 5, can be created.

Fig 6 shows the integration class model of the humanoid robot arm structure that will be developed.

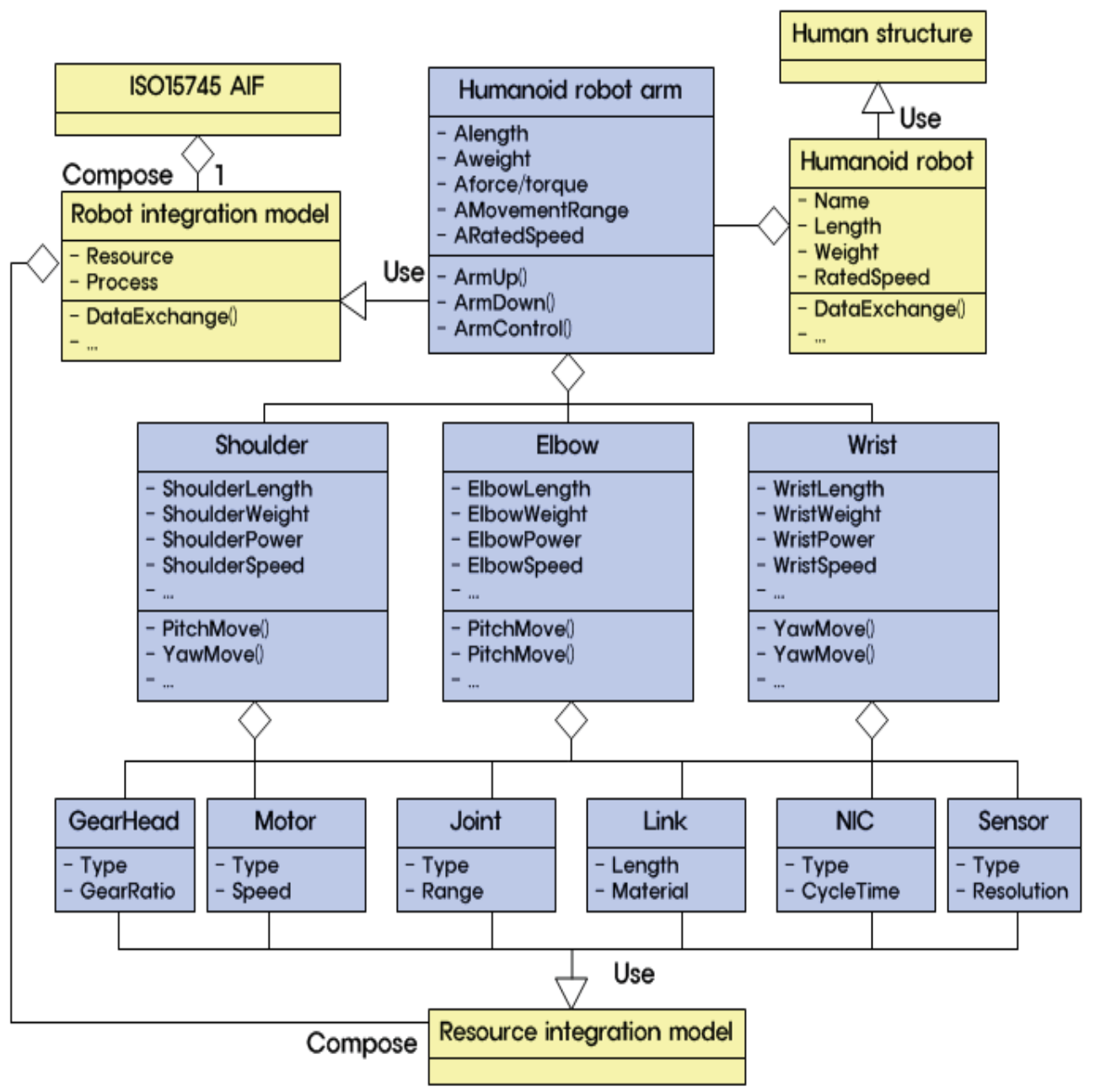

Fig. 6. Integration class model for humanoid robot arms

D. Humanoid robot arm design profile

In order to write up XML standard profile for humanoid robot arm, we must define DTD(Data type definition), schema that defines basic structure of XML documents. Fig. 7 represents standard profile of XML of humanoid robot arm that has been object instance based on XML schema structure. 


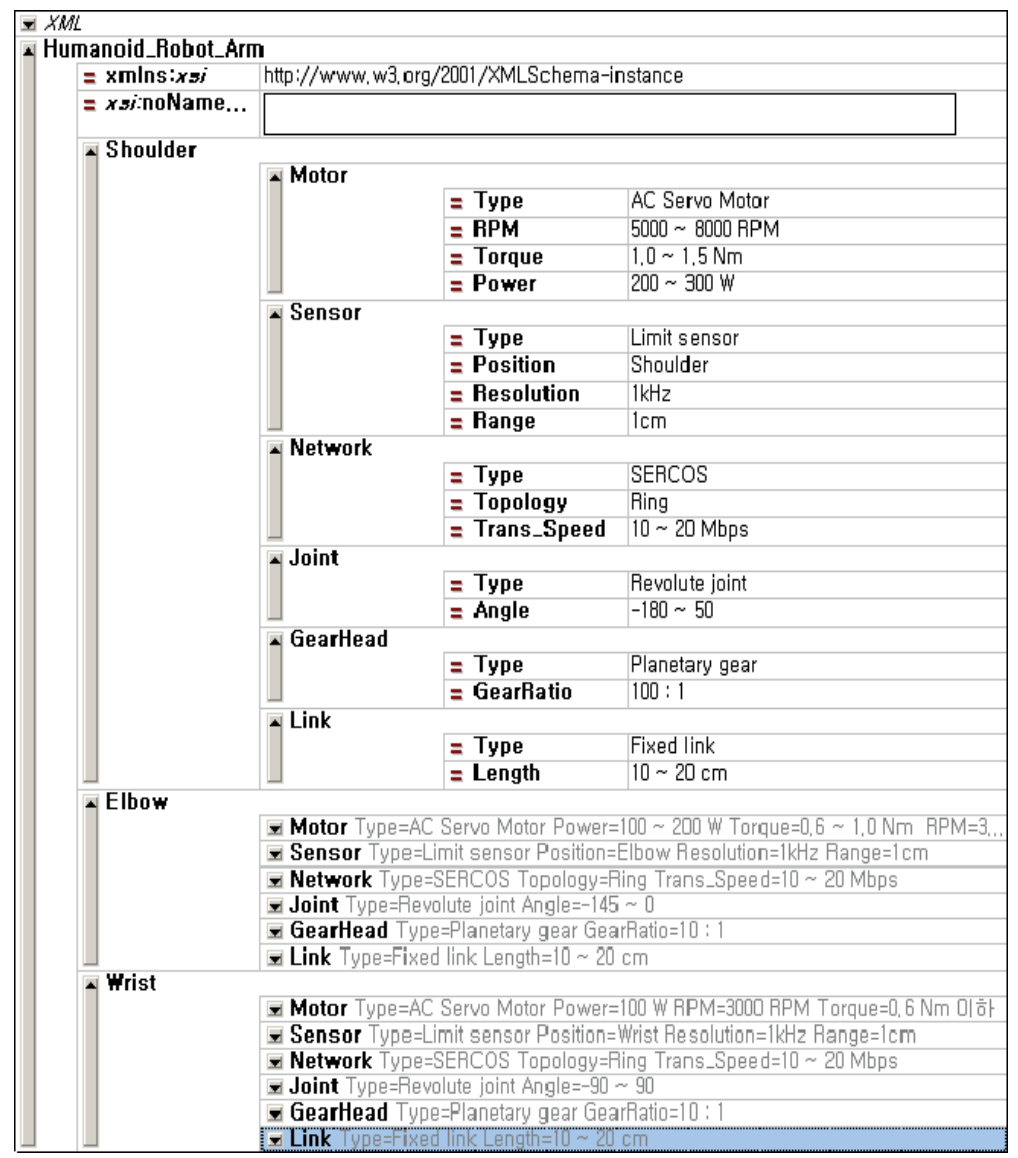

Fig. 7. XML profile for humanoid robot arm

\section{Sercos Based Robot Arm Design Analysis}

A. Humanoid robot arm structure and system

The degree of freedom of humanoid robot arm joints consist of total 5 degree of freedoms excluding 2 degrees of freedom from total 7 DOF of humans which are radial/ulnar and flection/extension. Moreover, humanoid robot arm control network and control system will consist of robotic arm control system that uses motion control SERCOS communication and high precision AC servo motors which can overcome problems that current humanoid robot system have.

Fig 8 represents concept of degrees of freedom and structure of humanoid robot arm that will be implemented to humanoid robot.

In conceptual diagram of Fig 8, among total seven degrees of freedom that humans have, except two degrees of freedom of wrist that have very little influence in motion control, the 
five degrees of freedom should be implemented including shoulder 3 degrees of freedom, elbow 1 degrees of freedom, wrist 1 degrees of freedom. Control motions that are related with the movement may deal the rest of 2 degrees of freedom.

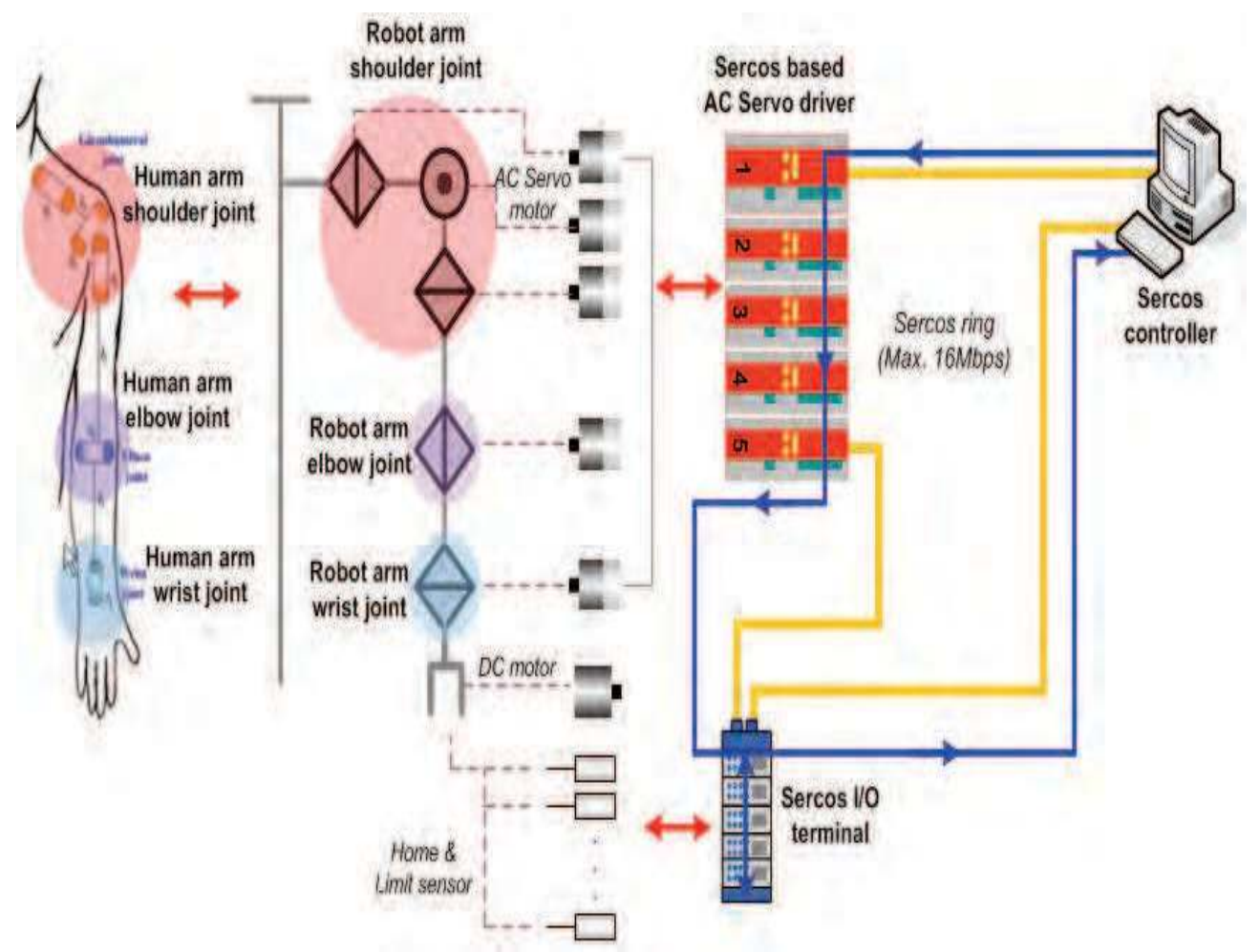

Fig. 8. The control system configuration of the humanoid robot arms

Unlike usual robot control method in microprocessor environment, SERCOS network based on humanoid robot arm control system in Fig. 8 uses SoftPLC(Software Programmable Logical Controller) technology which is the control method of constructing false image of continuous control environment in PC and uses mater/slave control method that is the method of continuous control through SERCOS communication.

The transfer of control data through SERCOS communication supports high speed transmission that speeds up to $16 \mathrm{Mbps}$, and it is possible to support precise motion of humanoid robot arm through standardized motion function block and to realize precision motion and synchronized control of separated humanoid robot joints.

Current International Motion Association provides standardized structure and function blocks for PTP motion control. In this paper, we tried to control the motion of humanoid robot arm by applying standardized PTP (point to point) control system and interpolation control.

Fig. 9 represents basic movement structure of state chart model that defines movement of standardized PTP motion control method. 


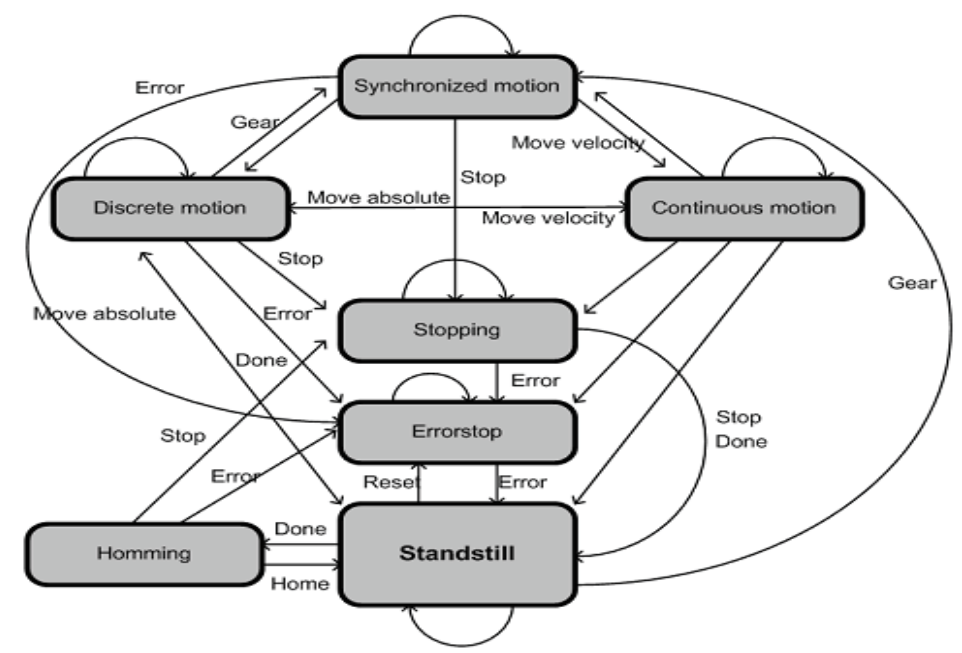

Fig. 9. The configuration drawing for the standard control function block and the condition

Interpolation control is the method for path driving of mutual interpolation of variety of axes in space that has been proposed to overcome disadvantage of PTP control method. Interpolation control, instead of control over discontinuous section, was optimal for continuous section.

Moreover, it is possible to make continuous section during discontinuous section using interpolation control like in Fig. 10.

In order for interpolation control to work properly for humanoid robot arm in various environments, detailed processes of motion interrupter establishment and control should be implemented additionally.
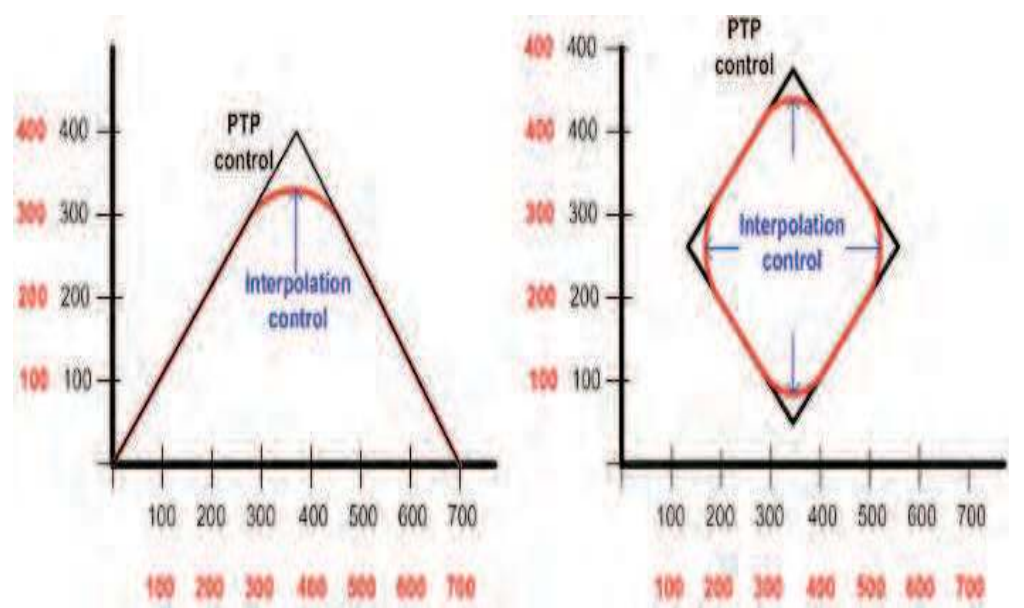

Fig. 10. Motion trace from interpolation control and PTP control 


\section{Humanoid Robot Arm Implementation and Evaluation}

The humanoid robot arm in the right side of Fig. 11 was implemented with international standard motion control SERCOS network and AC servo control system. Each arm links machinery module structure that is possible to attached and remove.

The measurement and calculation for kinematics of matrix of humanoid robot arm motion tracing has been implemented through visual $\mathrm{C}++$. Fig. 11 also shows the experimental diagram for humanoid robot arm motion control and calculation for tracing of rotational angel with input condition by using kinematics model.

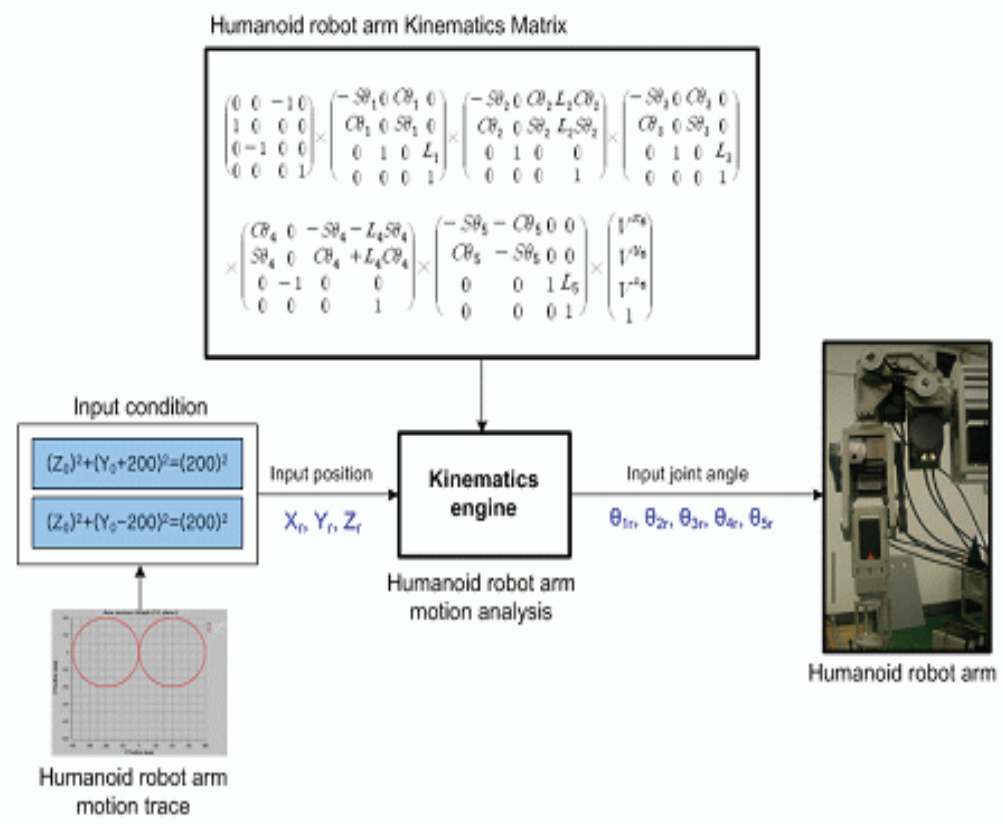

Fig. 11. The structure of calculating the information for the join rotation of humanoid robot arm

By using 3 dimensional space coordinating calculation of robot for input of kinematics matrix for rotational angle of 5 joints of humanoid robot arm measured during motion trace used as the method of measuring motion trace of humanoid robot arm, we used method of yielding real motion trace value of humanoid robot arm.

In Fig 11, we performed performance evaluation for circle motion control of humanoid robot arm using control performance, motion trace measurement, and calculation structure. In this paper, we used double circle trace for the purpose of humanoid robot arm motion control. Fig. 12 represents structure of double circle trace to be inputted for circle motion control of humanoid robot arm.

In Fig. 13, rotational angle information that will be used as humanoid robot arm was produced by input of position value of circle trace of desired formula for kinematics matrix. 
Since induced input joint rotational angle is dependent on kinematics matrix, in case of induction of real kinematics matrix does not occur properly, we must use properly induced kinematics matrix. Otherwise, it will cause totally difference output of desired motion due to production of false input information.
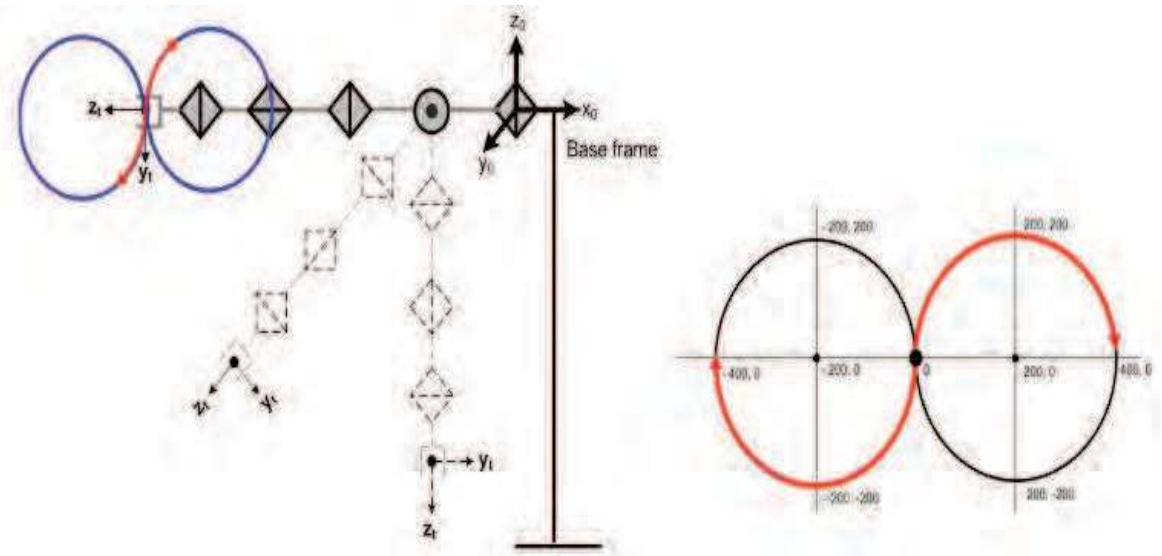

Fig. 12. The outline of the circle motion control trace setting for the humanoid robot arms

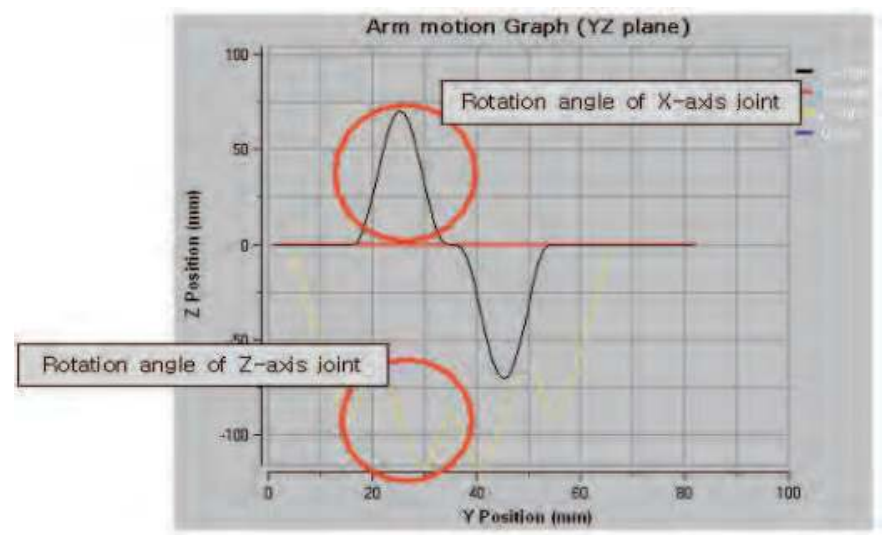

Fig. 13. Circle control input degree trace

As we know input angle trace information from Fig. 14, we know it can be formed by driving two joints that are circular traces. Furthermore, we created one circular trace through the rotational angel trace of cosine type to determine direction of motion trace and the rotational angel trace of sine type to determine position of motion trace.

Fig. 14 shows repeated motion trace and normal circular trace during the 5 repeating motion trace as a PTP output trace for double circular motion with input rotation angel.

As we know through the circular control trace of PTP from Fig. 14, the repeated position precision of trace is superior to position repeating precision trace itself. However, precision 
of position tracking for actual desired circular motion is fairly poor in the PTP control case of humanoid robot arm.
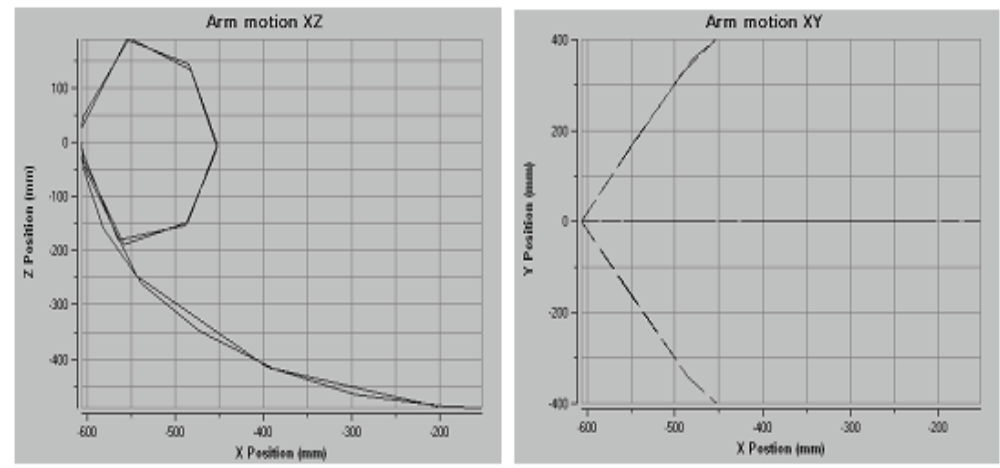

Fig. 14. Result of the circle PTP control trace from plane (XZ, XY)

In this paper, in order to solve PTP control problem of low precision, we applied interpolation control which is an optimal control for continuous section in the 3D space. Fig. 15 shows repeated motion trace and normal circular trace during the 5 repeats as an interpolation control input trace for double circular motion with input rotational angel.
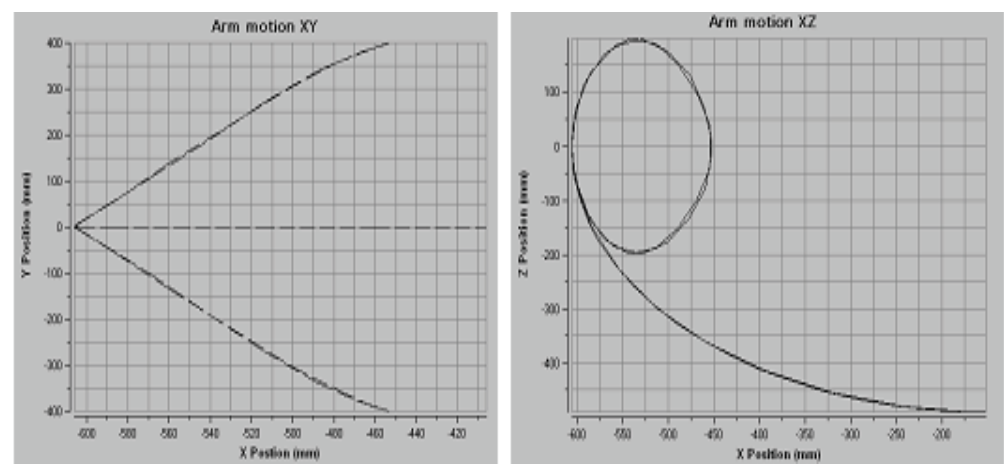

Fig. 15. Result of the circle interpolation control trace from plane $(X Z, X Y)$

We can see the interpolation control which has smoother trace and high precision that is superior to PTP control. There are a small error found between the actual trace and the interpolation control trace. The comparison of PTP and interpolation control represented in Fig. 14 and Fig. 15.

Fig. 16 shows measurement of trace for error between the interpolation control and actual circular control. Since the errors that occur in each section of real control sampling are different, we used mean error for each section and evaluated tracking error that occur in peak location dot tracking for error section and repeating error that represents floating ratio that occurs between sections. Calculated error value from measurement is represented in Fig 16. 


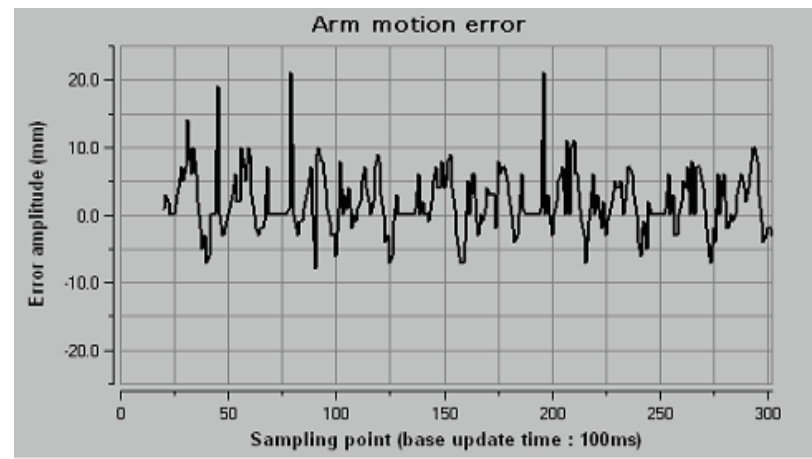

Fig. 16. Circle control error output (motion 5 times repetition error)

Table 2 represent the motion error measurement data of the humanoid robot arm. Through the 5 controls, we found that mean position trace error is about $4.112 \mathrm{~mm}$ and mean position repetition error is about $0.135 \mathrm{~mm}$ in the Table 2 .

\begin{tabular}{|c|c|c|c|}
\hline Times & Sampling time $(\mathrm{ms})$ & $\begin{array}{c}\text { Sum of } \\
\text { error }(\mathrm{mm})\end{array}$ & Mean error $(\mathrm{mm})$ \\
\hline 1 & $\begin{array}{c}50 \text { Point } \\
(5 \mathrm{~s} / 0.1 \mathrm{~s}(100 \mathrm{~ms})\end{array}$ & $204 \mathrm{~mm}$ & $204 / 50=4.08 \mathrm{~mm}$ \\
\hline 2 & $\begin{array}{c}50 \text { Point } \\
(5 \mathrm{~s} / 0.1 \mathrm{~s}(100 \mathrm{~ms})\end{array}$ & $209 \mathrm{~mm}$ & $209 / 50=4.18 \mathrm{~mm}$ \\
\hline 3 & $\begin{array}{c}50 \text { Point } \\
(5 \mathrm{~s} / 0.1 \mathrm{~s}(100 \mathrm{~ms})\end{array}$ & $199 \mathrm{~mm}$ & $199 / 50=3.98 \mathrm{~mm}$ \\
\hline 4 & $\begin{array}{c}50 \text { Point } \\
(5 \mathrm{~s} / 0.1 \mathrm{~s}(100 \mathrm{~ms})\end{array}$ & $205 \mathrm{~mm}$ & $205 / 50=4.1 \mathrm{~mm}$ \\
\hline 5 & $\begin{array}{c}50 \text { Point } \\
(5 \mathrm{~s} / 0.1 \mathrm{~s}(100 \mathrm{~ms})\end{array}$ & $211 \mathrm{~mm}$ & $211 / 50=4.22 \mathrm{~mm}$ \\
\hline Total & $\begin{array}{c}|c| \\
\text { Mean poison repetition error }:(0.1+0.2+0.12+0.12) / 4= \\
0.135 \mathrm{~mm}\end{array}$ \\
\hline
\end{tabular}

Table 2. The motion error measurement data of the humanoid robot arms

\section{Conclusion}

In this paper, we have presented the implementation and performance evaluation for SERCOS based humanoid robot arm by using morphological and neurological analysis of human arm. Moreover, we reviewed the possibility of application of these robot arms. First, we proposed robot development methodology of open architecture based on ISO15745 for "opening of humanoid robot." Then, we verified the method of implementation of humanoid robot arm and its application to the real world.

We have implemented robot arm using SERCOS communication and AC servo motor for high precision motion control; in addition, we got a mean position trace error of $4.112 \mathrm{~mm}$ and mean position repetition error of $0.135 \mathrm{~mm}$ as a control performance. 


\section{References}

Karl Williams, "Build Your Own humanoid Robots", Tab Bookks, 2004.

Christopher E. Strangio, "The RS232 Standard - A Tutorial with Signal Names and Definitions" 1993 2006. "Universal Serial Bus Specification", Compaq, Intel, Microsof, NEC, 998.

Robot Bosch Gmbh, "CAN Specification v2.0", Bosch, 1991.

John F. Shoch, "An Introduction to the Ethernet Specification", ACM SIGCOMM Computer Communication Review volume 11, pp 17-19, New York, USA, 1981.

ISO TC 184/SC 5, "ISO 156745 - Industrial automation system and integration Part1, 1999.

David G. Amaral, "Anatomical organization of the central M. King, B. Zhu, and S. Tang, "Optimal path planning," Mobile Robots, vol. 8, no. 2, pp. 520-531, March 2001.

Rainer Bischoff, Volker Graefe, "HREMES-a Versatile Personal Robotic Assistant", IEEESpecial Issue on Huamn Interactive Robots for Psychological Enrichment, pp. 1759-1779, Bundeswehr University Munich, Germany.

In A. Zelinsky, "Design Concept and Realization of the humanoid Service Robot HERMES", Field and Service Robotics, London, 1998

Rainer Bischoff, "HERMES-A humanoid Mobile Manipulator for Service Task", International Conference on field and Service Robots, Canberra, December 1997.

Rainer Bischoff, "Advances in the Development of the humanoid Service Robot HERMES", Second International Conference on field and Service robotics, 1999.

H. Netter MD, "Atlas of Human Anatomy, Professional edition", W.B Saunders, 2006. Function blocks for motion control, "PLCopen-Technical Committee2", 2002. 


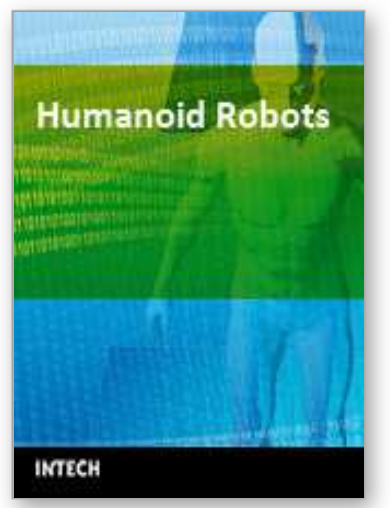

\author{
Humanoid Robots \\ Edited by Ben Choi
}

ISBN 978-953-7619-44-2

Hard cover, 388 pages

Publisher InTech

Published online 01, January, 2009

Published in print edition January, 2009

Humanoid robots are developed to use the infrastructures designed for humans, to ease the interactions with humans, and to help the integrations into human societies. The developments of humanoid robots proceed from building individual robots to establishing societies of robots working alongside with humans. This book addresses the problems of constructing a humanoid body and mind from generating walk patterns and balance maintenance to encoding and specifying humanoid motions and the control of eye and head movements for focusing attention on moving objects. It provides methods for learning motor skills and for language acquisition and describes how to generate facial movements for expressing various emotions and provides methods for decision making and planning. This book discusses the leading researches and challenges in building humanoid robots in order to prepare for the near future when human societies will be advanced by using humanoid robots.

\title{
How to reference
}

In order to correctly reference this scholarly work, feel free to copy and paste the following:

Yongseon Moon, Nak Yong Ko and Youngchul Bae (2009). The Design of Humanoid Robot Arm Based on Morphological and Neurological Analysis of Human Arm, Humanoid Robots, Ben Choi (Ed.), ISBN: 978-9537619-44-2, InTech, Available from:

http://www.intechopen.com/books/humanoid_robots/the_design_of_humanoid_robot_arm_based_on_morphol ogical_and_neurological_analysis_of_human_arm

\section{INTECH}

open science | open minds

\section{InTech Europe}

University Campus STeP Ri

Slavka Krautzeka 83/A

51000 Rijeka, Croatia

Phone: +385 (51) 770447

Fax: +385 (51) 686166

www.intechopen.com

\section{InTech China}

Unit 405, Office Block, Hotel Equatorial Shanghai

No.65, Yan An Road (West), Shanghai, 200040, China

中国上海市延安西路65号上海国际贵都大饭店办公楼 405 单元

Phone: +86-21-62489820

Fax: $+86-21-62489821$ 
(C) 2009 The Author(s). Licensee IntechOpen. This chapter is distributed under the terms of the Creative Commons Attribution-NonCommercialShareAlike-3.0 License, which permits use, distribution and reproduction for non-commercial purposes, provided the original is properly cited and derivative works building on this content are distributed under the same license. 